\title{
Mental health, violence and psychological coercion among female and male trafficking survivors in the greater Mekong sub-region: a cross-sectional study
}

\author{
Lisbeth Iglesias-Rios $^{1 *+}$ D, Siobán D. Harlow ${ }^{1+}$, Sarah A. Burgard ${ }^{2+}$, Ligia Kiss ${ }^{3}$ and Cathy Zimmerman ${ }^{3}$
}

\begin{abstract}
Background: Human trafficking is a pervasive global crime with important public health implications that entail fundamental human rights violations in the form of severe exploitation, violence and coercion. Sex-specific associations between types of violence or coercion and mental illness in survivors of trafficking have not been established.

Methods: We conducted a cross-sectional study with 1015 female and male survivors of trafficking (adults, adolescents and children) who received post-trafficking assistance services in Cambodia, Thailand or Vietnam and had been exploited in various labor sectors. We assessed anxiety and depression with the Hopkins Symptoms Checklist (HSCL-25) and post-traumatic stress disorder (PTSD) symptoms with the Harvard Trauma Questionnaire (HTQ), and used validated questions from the World Health Organization International Study on Women's Health and Domestic Violence to measure physical and sexual violence. Sex-specific modified Poisson regression models were estimated to obtain prevalence ratios (PRs) and their 95\% confidence intervals (Cl) for the association between violence (sexual, physical or both), coercion, and mental health conditions (anxiety, depression and PTSD).

Results: Adjusted models indicated that for females, experiencing both physical and sexual violence, compared to not being exposed to violence, was a strong predictor of symptoms of anxiety (PR $=2.08 ; 95 \% \mathrm{Cl}: 1.64-2.64)$, PTSD $(\mathrm{PR}=1.55 ; 95 \% \mathrm{Cl}: 1.37-1.74)$, and depression ( $\mathrm{PR}=1.57 ; 95 \% \mathrm{Cl}: 1.33-1.85)$. Among males, experiencing physical violence with additional threats made with weapons, compared to not being exposed to violence, was associated with PTSD (PR $=1.59 ; 95 \% \mathrm{Cl}: 1.05-2.42)$ after adjustment. Coercion during the trafficking experience was strongly associated with anxiety, depression, and PTSD in both females and males. For females in particular, exposure to both personal and family threats was associated with a 96\% elevated prevalence of PTSD (PR $=1.96 ; 95 \% \mathrm{Cl}: 1.32-2.91)$ and more than doubling of the prevalence of anxiety ( $P R=2.11 ; 95 \% \mathrm{Cl}: 1.57-2.83$ ).

Conclusions: The experiences of violence and coercion in female and male trafficking survivors differed and were associated with an elevated prevalence of anxiety, depression, and PTSD in both females and males. Mental health services must be an integral part of service provision, recovery and re-integration for trafficked females and males.
\end{abstract}

Keywords: Human trafficking, Forced labor, Violence, Coercion, Anxiety, Depression, PTSD, Females, Males

\footnotetext{
* Correspondence: lisgle@umich.edu

†Lisbeth Iglesias-Rios, Siobán D. Harlow and Sarah A. Burgard contributed

equally to this work.

'Department of Epidemiology, School of Public Health, University of

Michigan, 1415 Washington Heights, Ann Arbor, MI 48109, USA

Full list of author information is available at the end of the article
}

(c) The Author(s). 2018 Open Access This article is distributed under the terms of the Creative Commons Attribution 4.0 International License (http://creativecommons.org/licenses/by/4.0/), which permits unrestricted use, distribution, and reproduction in any medium, provided you give appropriate credit to the original author(s) and the source, provide a link to the Creative Commons license, and indicate if changes were made. The Creative Commons Public Domain Dedication waiver (http://creativecommons.org/publicdomain/zero/1.0/) applies to the data made available in this article, unless otherwise stated. 


\section{Background}

Modern slavery is the term that has emerged recently to encompass extreme forms of exploitation, including human trafficking, forced labor and forced marriage [1, 2]. These abuses are a pervasive global phenomena that have important implications for public health and human rights [1, 2]. Estimates suggest that 40.3 million women, men, and children are in modern slavery situations, with 24.9 million exploited as forced laborers in different economic sectors (e.g., fishing, agriculture, construction, domestic work) and 15.4 million in forced marriage conditions [2]. The Asia Pacific region accounts for the largest number of forced laborers, at $62 \%$ of the global total, where four out of every 1000 people suffer from labor exploitation [2].

Perpetrators of trafficking often assert their control and coercion, which are well-recognized tactics related to interpersonal violence (sexual, psychological, or physical), and frequently rely on taking advantage of an individual's particular vulnerabilities (e.g., age, sex) [3-6]. For instance, it is known that females trafficked for commercial sex and domestic work are subjected to high levels of sexual violence $[4,6]$. Additionally, perpetrators may take advantage of the inherent characteristics of the particular labor sector, such as its informality or engagement of irregular migrants, to assert their power over trafficked individuals [7]. This complex asymmetrical manifestation of power, control and violence over trafficked individuals and the fact that different forms of trafficking tend to be sex specific (i.e., females are more commonly exploited for sex work, men for fishing or construction) suggests that experiences of violence (e.g., sexual, physical or both) and coercion will differ for females and males [8-11]. However, to date, there has been limited sex-specific or comparative evidence on the mental health impact of human trafficking for different forms of labor exploitation or among culturally diverse populations of females and males (including adults, adolescents, and children). Most research on human trafficking has centered on sex trafficking and females, while other forms of forced labor and trafficking of males remains understudied. This in turn has led to an underestimate of the number of females and males affected by the different forms of exploitation in most locations [12, 13].

Scholars and experts have argued that "exploitation" is at the core of the definition of human trafficking or forced labor and that "coercion" is a key feature [4, 11, 14-16]. Psychological coercion (threats or deception) and violence (physical, sexual, or both) are interconnected and can be sources of traumatic and chronic stressors [3, 4, 17]. Indeed, trafficked individuals report similar experiences of violence, coercion and corresponding psychological consequences as prisoners of war, torture survivors, survivors of concentration camps, cult members, and victims of domestic violence [3, 4, 18-24]. Perpetrators exert high levels of power and control over victims' social, physical, psychological, sexual or economic milieu using systematic organized techniques of disempowerment and disconnection $[4,11,14]$.

The substantial inequalities in power and control that are experienced by trafficked individuals are associated with higher levels of physical, psychological, and sexual violence $[3,25]$. Deprived living conditions with profound restrictions on basic human needs (e.g., food, water, and shelter) during trafficking, and the fact that enslaved individuals may not be able to predict or control any aspect of their life circumstances, make trafficked individuals more susceptible to chronic disease and mental illness [11, 26-29]. Studies on human trafficking in females that used screening instruments to assess mental health have reported a very high prevalence of anxiety (48.0-97.7\%), depression (52.0-100\%), and post-traumatic stress disorder (PTSD, 19.5-77.0\%) [26, 30-33]. Only three studies have evaluated the mental health of trafficked males [34-36]. One [34] examined symptom associations with different levels of violence, while another reported only descriptive results for 27 males [36]. The third study included only 18 trafficked men who were in contact with secondary mental health services [35], therefore the past evidence is limited.

Studies conducted with trafficked females and males suggest that there are sex-related differences in survivors' mental health. The present study builds on earlier findings from the Study on Trafficking, Exploitation and Abuse in the Mekong Sub-region (STEAM) [34]. STEAM is a pioneering study as the first and largest health survey of trafficking survivors exploited in various labor sectors among a diverse Southeast Asian population of females and males, including children and adolescents using post-trafficking services [34]. The aim of the study was to examine the experience of violence and coercion in relation to mental health (anxiety, depression, and PTSD) of female and male trafficking survivors. To our knowledge, no studies to date have assessed the sex-specific associations between types of violence or coercion and mental illness in survivors of trafficking. Throughout the paper, the terms human trafficking and forced labor are used interchangeably.

\section{Methods}

\section{Data source, study design, and study sample}

This study is a cross-sectional secondary analysis using data from the STEAM. The study methodology has been published elsewhere [34]. The study sample included 1015 survivors: trafficked males, females, adolescents, and children (aged 10-17 years) who reached the 
country of exploitation and attended post-trafficking assistance services in Cambodia, Thailand, or Vietnam.

\section{Sample design}

A two-stage sampling strategy was used to identify individuals using post-trafficking services. First, 15 post-trafficking support service organizations were selected across the three countries (6 services in Cambodia, 4 in Thailand, and 5 in Vietnam) based on diversity of clientele (e.g., age, sex, sector of exploitation, and country of origin), service relationship with the International Office of Migration (IOM) country teams, and agreements with government agencies (e.g., support, referral, and service arrangements). The STEAM describes individuals who received post-trafficking services, regardless of differing legal definitions of trafficking and service eligibility criteria between countries [34].

Second, a consecutive sample of individuals were invited to participate in a structured interview within 2 weeks of admission to the post-trafficking services between October 2011 and May 2013. Participants were recruited only if the locally-trained caseworker or social worker determined that their participation would not cause harm to their well-being. Individuals in the sample were identified as trafficked by the local governmental and non-governmental referral networks and post-trafficking service providers. The response rate for the baseline survey was $98 \%$.

\section{Data collection}

Interviews were conducted by caseworkers or social workers from the agencies providing post-trafficking services. Interviewers received an intense one-week training provided by one of the principal investigators of the STEAM (LK) in collaboration with the IOM partners in each country. Data collection and double data entry were coordinated by IOM country offices, with oversight by the London School of Hygiene and Tropical Medicine (LSHTM).

\section{Development of survey questionnaire and application}

The survey questionnaire was based on the instrument used in a previous European study on health and sex trafficking [28] and adapted by the study team for the different study populations (various labor forms of exploitation) and the regions studied by STEAM. The interviewers also participated in adapting the questionnaire, which was pilot tested in the study settings. The survey included questions about socioeconomic background, pre-trafficking and post-trafficking exposures, living and working conditions during trafficking, violence and coercive factors, mental and physical health outcomes, and future plans and concerns. The instrument was translated into Khmer, Thai, Vietnamese, and Lao in multiple steps: professional translation from English to other languages, group translation-discussion processes with IOM countertrafficking teams, pilot-testing, and review after backtranslation into English.

\section{Ethics}

A strict ethical and safety protocol was implemented based on the World Health Organization (WHO) Ethical and Safety Recommendations for Interviewing Trafficked Women [37]. Ethical approval for the study was granted by the LSHTM and by the National Ethics Committee for Health Research in Cambodia, the Hanoi School of Public Health in Vietnam, and the Ministry of Social Development and Human Security in Thailand. Core ethical guidance included measures to ensure that participation was voluntary and confidential, assurance that declining participation would not affect the provision of support services, avoidance and management of distress, and the offering of options for supported referral for health or other problems. The secondary analysis was approved by the University of Michigan Health Sciences and Behavioral Sciences Institutional Review Board, eResearch ID: HUM00097096.

\section{Specific measures \\ Anxiety, depression, and post-traumatic stress disorder symptoms measures}

Anxiety and depression symptoms in the past week were measured by the Hopkins Symptom Checklist-25, a symptom inventory [38]. It consists of 25 items: 10 for anxiety symptoms and 15 for depression symptoms. The scale for each item includes four categories of response ("Not at all," "A little," "Quite a bit," and "Extremely," rated 1 to 4 , respectively). The anxiety score was calculated as the average of the anxiety items, while the depression score was the average of the depression items. The depression score has been correlated with major depression as defined by the Diagnostic and Statistical Manual of the American Psychiatric Association, 4th edition (DSM-IV) in several populations [39]. A cutoff of 1.625 instead of the established value of 1.75 was used to identify symptoms of depression, as item 12 in the questionnaire (i.e., loss of sexual interest or pleasure) was excluded, given the nature of the study population [34]. For anxiety, a cutoff of 1.75 indicated symptoms of anxiety, based on previous research on individuals using post-trafficking services and on studies of Cambodian, Laotian, and Vietnamese refugees with whom this instrument has been validated [31, 36, 40, 41].

PTSD symptoms in the past week were measured using the Harvard Trauma Questionnaire (HTQ) part IV, which includes 27 trauma symptoms [42]. The first 16 items were derived from the DSM-IV criteria for PTSD and assessed the presence of the main PTSD symptom clusters: intrusive experiencing, 
avoidance behaviors, hypervigilance, and emotional numbing [39]. The remaining items were developed by the Harvard Program in Refugee Trauma. These PTSD symptom items focus on the impact that the traumatic experiences may have had on the subject's perception of his or her daily life (e.g., having difficulty dealing with new situations) [42-44]. Each question has four response categories: "Not at all," "A little," "Quite a bit," and "Extremely," rated 1 to 4, respectively. A total score was calculated by averaging the 27 items. A cutoff of 2.0 was used to assess symptoms of PTSD based on previous research on trafficked individuals accessing post-trafficking services [30, 32]. Although the HTQ has not been validated with the study population, it has been used in cross-cultural settings and among Southeast Asian populations (e.g., Cambodians) exposed to trauma [40, 45, 46]. This instrument has shown high sensitivity for identifying persons with PTSD when diagnosed by experienced psychiatrists in a clinical setting and according to DSM criteria [40]. The HTQ has high reliability [47] and internal consistency $[47,48]$ and test-retest reliability ranging from 0.89 to $0.92[48,49]$.

\section{Violence and coercion measures}

To assess physical and sexual violence, standardized and validated questions from the World Health Organization (WHO) International Study on Women's Health and Domestic Violence were used [13]. These questions describe acts of physical and sexual violence commonly reported by trafficked individuals in post-trafficking services and shelters $[4,30,34,36]$. For females, we created a three category indicator of: "no violence", "physical violence only", "sexual violence only", and "physical and sexual violence." "Physical violence only" indicated the experience of any violent acts such as: being kicked, dragged, or beaten up; being tied or chained, choked, or burned; having a dog released to bite or scratch; being threatened with a weapon, cut with a knife, or being shot at, experiencing punches, slaps, and hits, but no experience of sexual violence. "Sexual violence only" was defined by a positive response to one item asking whether the respondent was forced to have sex, but no experience of physical violence, and lastly, those in the "physical and sexual violence" category were exposed to both types. These categorizations were based on previous research with survivors of trafficking [26, 28, 34]. For males, violence (yes/no) was measured with the variable "physical violence with additional threats made with a gun, knife, or other weapon" as only six males reported sexual violence. This variable included all the acts of physical violence listed above with additional threats made with weapons. We also identified in descriptive analysis that the experience of violence in males was for the most part defined by this type of physical violence.

Two additional questions were used to assess coercion during the trafficked period for females and males: (a) "While you were in this situation, did anyone threaten to hurt you?" (yes or no) and (b) "During this time did anyone threaten to hurt your family or someone you care about?" (yes or no). These questions assess threats commonly made by traffickers that are considered hallmarks of the trafficking experience and are frequently used in studies of interpersonal violence $[14,28,34,50]$.

\section{Covariates}

Covariates in this analysis were theory-driven and based on prior analyses of the STEAM [11, 32, 34, $51]$, and included age $(10-17,18-25$, and 26 or above), country of exploitation and trafficking (Thailand, China, or Other [Cambodia, Malaysia, Vietnam, Indonesia, Mauritius, South Africa, and Russia]), and time in trafficking (1-12 and 13 or more months). Participants were asked which trafficking sector they were exploited in most recently. The grouping of sectors of exploitation was based on similarity of occupational exposures and risks, balanced with the need to group sectors together due to low counts in particular occupations. Sectors for females and males were grouped together as sex work, forced marriage, entertainment, and dancing (sex and entertainment industry); domestic work, cleaning, restaurant work, and begging (hospitality industry and begging); construction and factory work (manufacturing industry); and livestock, meat packing and preparation, agriculture, or fishing (animal and agriculture industry). For males, we further collapsed the sex and entertainment industry with the hospitality industry and begging sectors to be able to make meaningful comparisons, since there were few individuals in those sectors. Groupings of sectors of exploitation were also based on previous research that indicates that some of these labor sectors might share similar levels of violence [32, 34, 52].

\section{Statistical analyses}

Because of important differences in the distribution of violence, coercion and trafficking-related exposures, the analyses were stratified by sex. We calculated frequencies and conducted bivariate analyses with cross tabulations using Rao-Scott chi-square tests to account for the clustered structure of the data (i.e., post-trafficking service organizations) and assess associations between violence, coercion (threats) and covariates with anxiety, depression, and PTSD symptoms [53]. Sex-specific unadjusted and adjusted modified Poisson regression models were conducted 
to estimate prevalence ratios (PRs) and their 95\% confidence intervals (CIs) for the associations between violence and coercion with anxiety, depression, and PTSD [54].

Generalized estimation equations (GEEs) with an extension of the sandwich variance estimator were used to calculate a robust variance estimation that considers the level of correlation of observations within a cluster and produces standard errors of the estimates accordingly [55]. This statistical approach was chosen because it is considered to be a direct and less-biased approach to estimating the PRs. This method corrects standard errors, considers clustered data $[54,56,57]$, and it is robust to the specification of the working correlation structure chosen [58].

To determine the best fit of the model and the working correlation structure, we used the quasi-likelihood under the independence model criterion (QIC) statistic, which is robust to the selection of correlation structure [59]. We chose an exchangeable correlation structure that assumes that all pairs of observations are correlated within a cluster. We fit separate and sex-specific binary modified Poisson regression models for each of the outcome variables (anxiety, depression, and PTSD). We fit a crude model for females and males with the previously specified demographic covariates only and separate crude and adjusted models for violence (model 1) and coercion (model 2) with each of the mental health outcomes. Given the low number of missing data (e.g., one female and one male were missing for anxiety, depression, and PTSD) we allowed for listwise deletion in all analytical models. All tests were two-tailed and analyses were performed using SAS version 9.4 (SAS Institute, Inc., Cary, NC). PROC SURVEYFREQ with a cluster and chisq statement were used for the descriptive analysis. PROC GENMOD was used with the robust variance estimator provided by the REPEATED statement with a cluster identifier that uses the method of GEE to estimate the model and give a proper estimate of the standard error of the PRs while accounting for clustering in the data.

\section{Results}

\section{Sample characteristics of females and males}

Table 1 presents descriptive characteristics of the study population stratified by sex. A total of 569 (56.1\%) females and 446 (43.9\%) males participated in the survey. The mean age $( \pm \mathrm{SD})$ of the study population was 22.8 years old \pm 8.4 years. Almost half of the females were children and adolescents $(<18$ years of age, 49.4\%), from Vietnam (41.8\%). Males were mainly $18-25$ years old (45.1\%), or older than 25 years old (40.8\%) and most frequently were from Cambodia $(57.6 \%)$. More than half of the population of females was exploited in Thailand (54.1\%) and more than a third in China (39.2\%). In contrast, $31.4 \%$ of males were trafficked in Thailand, $24.0 \%$ were trafficked in China.

Most females were trafficked for sex work, forced marriage, entertainment, and dancing (72.1\%) in Thailand (43.9\%) and China (25.8\%). In contrast, males were exploited mainly in sectors related to livestock (including meat preparation), agriculture, and fishing (67.0\%) and construction and factory work (23.0\%) in Thailand and various other countries (Cambodia, Malaysia, Vietnam, Indonesia, Mauritius, South Africa, and Russia). The vast majority of individuals were trafficked for more than 1 year irrespective of sex: $85.5 \%$ of females and $94.4 \%$ of males.

Approximately half of the participants, $52.1 \%$ of females and $49.3 \%$ of males, reported no experience of violence. Males experienced more episodes of physical violence only $(49.2 \%)$, while for females, violence involved physical (12.9\%) or sexual violence (15.7\%) alone, or both physical and sexual violence (19.3\%). Receiving personal threats was almost twice as common for males $(46.2 \%)$ as for females $(24.8 \%)$. In contrast, experiencing both personal and family threats was slightly more common for females $(14.6 \%)$ than for males (10.8\%). Half of the males (50.5\%) and a third of females (32.2\%) were subjected to physically violent acts that involved additional threats made with a gun, knife, or other weapon.

Table 2 presents information on the prevalence of anxiety, depression, and PTSD for females and males. The prevalence of depression was higher in women but present in more than half of the entire study population: $64.3 \%$ of females and $57.3 \%$ of males. PTSD was reported by about two-fifths of males (41.8\%) compared to about a third of females (34.5\%). Anxiety was experienced by more than two fifths in both females (40.5\%) and males (45.8\%).

\section{Modified Poisson regression models in females}

Results from the crude prevalence ratios of demographic characteristics and anxiety, PTSD, and depression are presented in Table 3.

Compared to children and adolescents (10-17 years old), the prevalence of anxiety for younger females (18-25 years old) was $26 \%$ ( $\mathrm{PR}=1.26$; 95\% CI: 1.12 1.42) higher. For young and older adults the prevalence of PTSD and depression was slightly elevated but it was not statistically signifcant when compared to minors. Females exploited in China had a $15 \%$ higher prevalence of depression $(\mathrm{PR}=1.15 ; 95 \% \mathrm{CI}$ : 1.01-1.32) compared to females trafficked in Thailand.

Females 1doing domestic work, cleaning, restaurant work, begging, and doing other forced labor had a $34 \%$ $(\mathrm{PR}=1.34 ;$ 95\% CI: 1.06-1.70) higher prevalence of 
Table 1 Sociodemographic characteristics of trafficking survivors by sex: The Study on Trafficking, Exploitation and Abuse in the Mekong Sub-region (STEAM), $\mathrm{n}=1015$

\begin{tabular}{|c|c|c|c|}
\hline & Females & Males & \\
\hline & n (\%) & n (\%) & $p$-value \\
\hline Total & $569(56.1)$ & $446(43.9)$ & \\
\hline Age & & & 0.03 \\
\hline $10-17$ & $281(49.4)$ & $63(14.1)$ & \\
\hline $18-25$ & 197 (34.6) & $201(45.1)$ & \\
\hline 26 or above & $91(16.0)$ & $182(40.8)$ & \\
\hline Country of origin & & & 0.0001 \\
\hline Cambodia & $49(8.6)$ & $257(57.6)$ & \\
\hline Vietnam & $238(41.8)$ & $106(23.8)$ & \\
\hline Other $^{a}$ & $282(49.6)$ & $83(18.6)$ & \\
\hline Country of exploitation & & & 0.001 \\
\hline China & $223(39.2)$ & $107(24.0)$ & \\
\hline Thailand & $308(54.1)$ & $140(31.4)$ & \\
\hline Other ${ }^{\mathrm{b}}$ & $38(6.7)$ & $199(44.6)$ & \\
\hline Sector of exploitation & & & $0.001^{d}$ \\
\hline Sex work, forced marriage, entertainment, and dancing ${ }^{c}$ & $410(72.1)$ & $46(10.3)$ & $0.006^{\mathrm{e}}$ \\
\hline Domestic work, cleaning, restaurant work, begging, and other & $66(11.6)$ & & \\
\hline Construction and factory work & $54(9.5)$ & $101(22.7)$ & \\
\hline Livestock, agriculture, fishing & $39(6.9)$ & $299(67.0)$ & \\
\hline Time in trafficking situation (months) ${ }^{f}$ & & & 0.002 \\
\hline $1-12$ & $78(14.5)$ & $24(5.7)$ & \\
\hline 13 or more & $460(85.5)$ & $401(94.4)$ & \\
\hline Violence during trafficking ${ }^{g}$ & & & $0.004^{h}$ \\
\hline No violence & $295(52.1)$ & $219(49.3)$ & \\
\hline Physical violence & $73(12.9)$ & $218(49.2)$ & \\
\hline Sexual violence & $89(15.7)$ & $0(0)$ & \\
\hline Both physical and sexual violence & 109 (19.3) & $6(1.4)$ & \\
\hline Receiving threats during trafficking & & & 0.0001 \\
\hline None & $345(60.6)$ & $192(43.1)$ & \\
\hline Personal threats & $141(24.8)$ & $206(46.2)$ & \\
\hline Both, personal and family threats & $83(14.6)$ & $48(10.8)$ & \\
\hline Physical violence with threats made with a gun, knife, or other weapon during trafficking ${ }^{i}$ & & & 0.20 \\
\hline Yes & $182(32.2)$ & $225(50.5)$ & \\
\hline No & $384(67.8)$ & $221(49.6)$ & \\
\hline
\end{tabular}

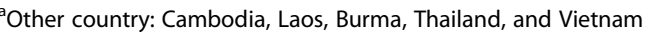

b Other country: Cambodia, Malaysia, Vietnam, Indonesia, Mauritius, South Africa, and Russia

${ }^{c} 43.9 \%$ and $25.8 \%$ of females in this sector of exploitation were exploited in Thailand and China, respectively

${ }^{\mathrm{d}} p$-value for females

e $p$-value for males. For males, we collapsed together the sex work, forced marriage, entertainment, dancing, domestic work, cleaning, restaurant work, begging,

and other due to small sample size across those sectors $(n=46)$

$\mathrm{f}_{31}$ females and 21 males missing

${ }_{3}$ females and 3 males missing

${ }^{\mathrm{h}} p$-value for females

i 3 females missing 
Table 2 Prevalence of mental health symptoms among trafficked survivors by sex, $\mathrm{n}=1015$

\begin{tabular}{|c|c|c|c|}
\hline & Females & Males & $p$-value \\
\hline & n (\%) & n (\%) & \\
\hline Anxiety $^{a}$ & & & 0.08 \\
\hline Yes & $230(40.5)$ & $204(45.8)$ & \\
\hline No & $338(59.5)$ & $241(54.2)$ & \\
\hline Depression $^{\mathrm{b}}$ & & & 0.02 \\
\hline Yes & $365(64.3)$ & $255(57.3)$ & \\
\hline No & $203(35.7)$ & $190(42.7)$ & \\
\hline Post-traumatic stress disorder (PTSD) ${ }^{c}$ & & & 0.02 \\
\hline Yes & $196(34.5)$ & $186(41.8)$ & \\
\hline No & $372(65.5)$ & $259(58.2)$ & \\
\hline
\end{tabular}

a,b,c1 female \& 1 male missing for anxiety, depression, and PTSD

anxiety and almost a 50\% elevated prevalence of PTSD $(\mathrm{PR}=1.49$; 95\% CI: 1.05-2.11) compared with those in sex work, forced marriage, entertainment or dancing. Similarly, women and girls exploited in construction and factory work had a $50 \%(\mathrm{PR}=1.50 ; 95 \% \mathrm{CI}: 1.12-2.03)$ greater prevalence of anxiety and a $47 \%$ elevated prevalence of PTSD ( $\mathrm{PR}=1.47 ; 95 \% \mathrm{CI}$ : $1.05-2.05)$. Time in trafficking was not statistically associated with any of the three mental health outcomes.

\section{Crude and adjusted prevalence ratios of the association of violence and coercion (threats) with anxiety, PTSD, and depression in trafficked females}

Table 4 shows the results from the crude and adjusted modified Poisson regression models for violence, coercion, and mental health outcomes in females. Multivariable models were adjusted for age, country of exploitation, sector of exploitation, and time in trafficking.

\section{Anxiety in females}

Females exposed to both physical and sexual violence had a $68 \%$ greater prevalence of anxiety ( $P R=1.68 ; 95 \%$ CI: 1.37-2.07), compared to those who did not report experiencing violence. After adjustment, the prevalence was elevated such that females exposed to both physical and sexual violence had a twofold higher ( $\mathrm{PR}=2.08 ; 95 \%$ CI: 1.64-2.64) prevalence of anxiety. Women and girls who suffered from physical violence alone had a $30 \%$ elevated prevalence of anxiety ( $\mathrm{PR}=1.31 ; 95 \% \mathrm{CI}: 1.06-$

Table 3 Crude prevalence ratios of demographic characteristics and anxiety, post-traumatic stress disorder, and depression in trafficked females, $n=569$

\begin{tabular}{|c|c|c|c|c|c|c|}
\hline & \multicolumn{2}{|c|}{ Anxiety } & \multicolumn{2}{|c|}{ PTSD $^{a}$} & \multicolumn{2}{|c|}{ Depression } \\
\hline & $\overline{P R^{b}}$ & $95 \% \mathrm{Cl}^{\mathrm{C}}$ & $\overline{P R}$ & $95 \% \mathrm{Cl}$ & $\overline{P R}$ & $95 \% \mathrm{Cl}$ \\
\hline \multicolumn{7}{|l|}{ Age } \\
\hline 10-17 (reference) & 1.0 & & 1.0 & & 1.0 & \\
\hline $18-25$ & 1.26 & $1.12-1.42^{* * *}$ & 1.12 & $0.96-1.30$ & 1.09 & $0.97-1.22$ \\
\hline 26 or above & 1.26 & $0.93-1.70$ & 1.15 & $0.86-1.53$ & 1.02 & $0.85-1.24$ \\
\hline \multicolumn{7}{|l|}{ Country of exploitation } \\
\hline Thailand (reference) & 1.0 & & 1.0 & & 1.0 & \\
\hline China & 1.34 & $0.87-2.07$ & 1.57 & $0.81-3.01$ & 1.15 & $1.01-1.32^{*}$ \\
\hline Other $^{d}$ & 1.76 & $1.14-2.73^{* *}$ & 1.80 & $0.89-3.63$ & 1.05 & $0.56-1.94$ \\
\hline \multicolumn{7}{|l|}{ Sector of exploitation } \\
\hline Sex work, forced marriage, entertainment, dancing (reference) & 1.0 & & 1.0 & & 1.0 & \\
\hline Domestic work, cleaner, restaurant work, begging, and other & 1.34 & $1.06-1.70^{* *}$ & 1.49 & $1.05-2.11^{*}$ & 1.12 & $0.89-1.42$ \\
\hline Construction and factory work & 1.50 & $1.12-2.03^{* *}$ & 1.47 & $1.05-2.05^{*}$ & 1.12 & $0.78-1.60$ \\
\hline Livestock, agriculture, and fishing & 1.17 & $0.81-1.69$ & 1.07 & $0.91-1.26$ & 0.88 & $0.65-1.19$ \\
\hline \multicolumn{7}{|l|}{ Time in trafficking situation (months) } \\
\hline 1-12 (reference) & 1.0 & & 1.0 & & 1.0 & \\
\hline 13 or more & 1.05 & $0.63-1.74$ & 1.38 & $0.87-2.20$ & 1.22 & $0.84-1.77$ \\
\hline $\begin{array}{l}{ }^{*} p \leq 0.05 \\
{ }^{*} p \leq 0.01 \\
{ }^{* * * *} p \leq 0.001 \\
\text { apTSD Posttraumatic stress disorder } \\
\text { bPR Prevalence ratio } \\
\text { bPR } \\
{ }^{9} 95 \% \text { Confidence interval }\end{array}$ & & & & & & \\
\hline
\end{tabular}


Table 4 Crude and adjusted prevalence ratios of the association of violence and coercion (threats) with anxiety, post-traumatic stress disorder, and depression in trafficked females, $\mathrm{n}=569$

\begin{tabular}{|c|c|c|c|c|c|c|}
\hline & \multicolumn{2}{|c|}{ Unadjusted model } & \multicolumn{2}{|c|}{ Adjusted Model $1^{a}$} & \multicolumn{2}{|c|}{ Adjusted Model $2^{b}$} \\
\hline & $\overline{P R^{c}}$ & $95 \% \mathrm{Cl}^{\mathrm{d}}$ & $\overline{\mathrm{PR}}$ & $95 \% \mathrm{Cl}$ & $\overline{P R}$ & $95 \% \mathrm{Cl}$ \\
\hline \multicolumn{7}{|l|}{ Anxiety } \\
\hline \multicolumn{7}{|l|}{ Violence } \\
\hline No violence (reference) & 1.0 & & 1.0 & & & \\
\hline Physical violence only & 1.31 & $1.06-1.62^{* *}$ & 1.18 & $0.93-1.49$ & & \\
\hline Sexual violence only & 0.90 & $0.59-1.39$ & 0.94 & $0.48-1.83$ & & \\
\hline Both physical and sexual violence & 1.68 & $1.37-2.07^{* * *}$ & 2.08 & $1.64-2.64^{* * *}$ & & \\
\hline \multicolumn{7}{|l|}{ Receiving threats during trafficking } \\
\hline None (reference) & 1.0 & & & & 1.0 & \\
\hline Personal threats & 1.93 & $1.54-2.41^{* * *}$ & & & 1.93 & $1.55-2.42^{* * *}$ \\
\hline Both personal and family threats & 2.10 & $1.58-2.79^{* * *}$ & & & 2.11 & $1.57-2.83^{* * *}$ \\
\hline \multicolumn{7}{|l|}{ Post-Traumatic Stress Disorder } \\
\hline \multicolumn{7}{|l|}{ Violence } \\
\hline No violence (reference) & 1.0 & & 1.0 & & & \\
\hline Physical violence only & 1.32 & $1.16-1.50^{* * *}$ & 1.15 & $0.89-1.48$ & & \\
\hline Sexual violence only & 0.80 & $0.60-1.07$ & 0.84 & $0.52-1.34$ & & \\
\hline Physical and sexual violence & 1.33 & $1.18-1.51^{* * *}$ & 1.55 & $1.37-1.74^{* * *}$ & & \\
\hline \multicolumn{7}{|l|}{ Receiving threats during trafficking } \\
\hline None (reference) & 1.0 & & & & 1.0 & \\
\hline Personal threats & 1.49 & $1.16-1.92^{* * *}$ & & & 1.44 & $1.06-1.96^{*}$ \\
\hline Both personal and family threats & 1.95 & $1.35-2.82^{* * *}$ & & & 1.96 & $1.32-2.91^{* * *}$ \\
\hline \multicolumn{7}{|l|}{ Depression } \\
\hline \multicolumn{7}{|l|}{ Violence } \\
\hline No violence (reference) & 1.0 & & 1.0 & & & \\
\hline Physical violence only & 1.17 & $0.97-1.40$ & 1.12 & $0.96-1.32$ & & \\
\hline Sexual violence only & 0.96 & $0.79-1.16$ & 1.02 & $0.85-1.22$ & & \\
\hline Both physical and sexual violence & 1.44 & $1.23-1.68^{* * *}$ & 1.57 & $1.33-1.85^{* * *}$ & & \\
\hline \multicolumn{7}{|l|}{ Receiving threats during trafficking } \\
\hline None (reference) & 1.0 & & & & 1.0 & \\
\hline Personal threats & 1.46 & $1.18-1.81^{* * *}$ & & & 1.46 & $1.20-1.78^{* * *}$ \\
\hline Both personal and family threats & 1.51 & $1.21-1.87^{* * *}$ & & & 1.42 & $1.25-1.63^{* * *}$ \\
\hline
\end{tabular}

Models for anxiety, depression, and post-traumatic stress disorder symptoms were run separately but they were adjusted for the same variables

${ }^{*} p \leq 0.05$

$p \leq 0.01$

${ }^{* * *} p \leq 0.001$

${ }^{a}$ Adjusted Model 1 (violence): age, country of exploitation, sector of exploitation, time in trafficking

${ }^{\mathrm{b}}$ Adjusted Model 2 (coercion or threats): age, country of exploitation, sector of exploitation, time in trafficking

${ }^{\mathrm{C}} \mathrm{PR}$ Prevalence ratio

${ }^{\mathrm{d}} 95 \%$ Confidence interval

1.62) compared to females without violence; however, after adjustment, the estimate was reduced and they did not differ significantly from those not reporting violence. Sexual violence alone was not statistically associated with anxiety in the crude or adjusted models.

After adjustment, females who received personal threats during trafficking had a $93 \%(P R=1.93 ; 95 \%$ CI: $1.55-2.42)$ greater prevalence of anxiety compared to those without threats, while the prevalence of anxiety more than doubled among those who experienced both personal and family threats $(\mathrm{PR}=2.11 ; 95 \% \mathrm{CI}$ : $1.57-2.83)$.

\section{PTSD in females}

Women and girls exposed to physical violence only, or both physical and sexual violence, had more than a $30 \%$ 
elevated prevalence of PTSD in the crude model. After adjustment, females exposed to both physical and sexual violence had almost a $50 \%$ higher prevalence of PTSD $(\mathrm{PR}=1.55 ; 95 \% \mathrm{CI}: 1.37-1.74)$ compared to those who did not report violence. Neither form of violence alone (physical or sexual) was statistically associated with PTSD after adjustment.

Women and girls who experienced personal threats had a $49 \%(\mathrm{PR}=1.49$; 95\% CI: $1.16-1.92)$ elevated prevalence of PTSD while for those who received both personal and family threats the prevalence for PTSD almost doubled (PR $=1.95$; 95\% CI: $1.35-2.82)$, compared to females without threats in the crude model. After adjustment, the prevalence ratio for personal threats was slightly reduced and remained statistically significant $(\mathrm{PR}=1.44 ; 95 \% \mathrm{CI}: 1.06-1.96)$. Females exposed to both personal and family threats, had a $96 \%$ greater prevalence of PTSD (PR $=1.96 ; 95 \%$ CI: 1.32-2.91) that remained statistically significant after adjustment.

\section{Depression in females}

After adjustment, females who suffered from both physical and sexual violence had a $57 \%(\mathrm{PR}=1.57$; 95\% CI: $1.33-$ 1.85) higher prevalence for depression when compared to those not experiencing violence. Physical and sexual violence alone were not statistically associated with depression in crude and adjusted models. However, experiencing threats remained significantly associated after adjustment. Females who experienced personal threats had a $46 \%(\mathrm{PR}=1.46$; $95 \% \mathrm{CI}: 1.20-1.78)$ elevated prevalence for depression. Similarly, after adjustment of covariates, women and girls with both personal and family threats had a $42 \%(P R=1.42$; 95\% CI: 1.25-1.63) higher prevalence of symptoms of depression when compared to females without threats.

\section{Modified Poisson regression models in males}

Table 5 shows the crude prevalence ratios of demographic characteristics and anxiety, PTSD, and depression in males. Age was not significantly associated with anxiety and PTSD. However, compared to children and adolescents, older adults had a 43\% (PR = 1.43;95\% CI: $1.08-1.90)$ greater prevalence of depression. Males exploited in China and other countries had a threefold ( $P R=3.63 ; 95 \%$ CI: $2.58-5.12)$ and a twofold ( $\mathrm{PR}=2.89 ; 95 \% \mathrm{CI}: 2.04-4.11$ ) higher prevalence of PTSD, respectively, compared to those trafficked in Thailand. The prevalence of anxiety among men and boys trafficked for 13 or more months more than doubled $(\mathrm{PR}=2.31 ; 95 \% \mathrm{CI}: 1.28-4.16)$ compared to those trafficked for 1-12 months. However, there were no statistically significant differences between the length of time in trafficking and PTSD or depression among males.

\section{Crude and adjusted prevalence ratios of the association of violence and coercion (threats) with anxiety, PTSD, and depression in trafficked males}

Results for the crude and adjusted modified Poisson regression models for violence and coercion with anxiety, PTSD, and depression in males are presented in Table 6. Multivariable models were adjusted for age, country of exploitation, sector of exploitation, and time in trafficking.

\section{Anxiety in males}

The prevalence of anxiety decreased slightly and did not differ after adjustment among those who suffered from physical violence with additional threats made with a gun, knife, or other weapon compared to those not experiencing violence. Similar to the crude model and after adjustment, the prevalence of anxiety among males was more than $30 \%(\mathrm{PR}=1.33$; 95\% CI: $1.08-1.64)$ and almost $70 \%(P R=1.68 ; 95 \%$ CI: 1.43-1.97) higher among those who experienced personal threats and those who had experienced both personal and family threats, respectively, compared to those who had not.

\section{PTSD in males}

Males subjected to physical violence with additional threats made with weapons had almost a 60\% higher prevalence of PTSD (PR = 1.59; 95\% CI: 1.05-2.42) when compared to males without violence after adjustment. Men and boys who received personal threats, and those receiving personal and family threats, had a $75 \%(\mathrm{PR}=$ 1.75; 95\% CI: $1.51-2.03)$ and $62 \%(\mathrm{PR}=1.62 ; 95 \% \mathrm{CI}$ : 1.31-2.00) elevated prevalence for PTSD, respectively, when compared to males without threats and after adjustment.

\section{Depression in males}

The prevalence of depression and physical violence with additional threats made with a gun, knife, or other weapon was elevated but did not differ significantly in crude and adjusted models. After adjustment, males subjected to personal threats and both personal and family threats had a $46 \%(\mathrm{PR}=1.46 ; 95 \%$ CI: $1.35-1.57)$ and $33 \%$ $(\mathrm{PR}=1.33$; 95\% CI: 1.11-1.58) greater prevalence for depression, respectively compared to those who were not threatened.

\section{Discussion}

The study advances knowledge about the mental health consequences of various forms of violence and coercion during trafficking among female and male survivors who 
Table 5 Crude prevalence ratios of demographic characteristics and anxiety, post-traumatic stress disorder, and depression in trafficked males, $\mathrm{n}=446$

\begin{tabular}{|c|c|c|c|c|c|c|}
\hline & \multicolumn{2}{|c|}{ Anxiety } & \multicolumn{2}{|c|}{ PTSD $^{a}$} & \multicolumn{2}{|c|}{ Depression } \\
\hline & $\overline{P R^{b}}$ & $95 \% \mathrm{Cl}^{\mathrm{C}}$ & $\overline{P R}$ & $95 \% \mathrm{Cl}$ & $\overline{\mathrm{PR}}$ & $95 \% \mathrm{Cl}$ \\
\hline \multicolumn{7}{|l|}{ Age } \\
\hline 10-17 (reference) & 1.0 & & 1.0 & & 1.0 & \\
\hline $18-25$ & 1.14 & $0.64-2.06$ & 1.79 & $0.76-4.20$ & 1.41 & $0.95-2.09$ \\
\hline 26 or above & 1.06 & $0.64-1.76$ & 1.64 & $0.91-2.96$ & 1.43 & $1.08-1.90^{* *}$ \\
\hline \multicolumn{7}{|l|}{ Country of exploitation } \\
\hline Thailand (reference) & 1.0 & & 1.0 & & 1.0 & \\
\hline China & 1.33 & $0.68-2.59$ & 3.63 & $2.58-5.12^{* * *}$ & 1.60 & $0.91-2.82$ \\
\hline Other $^{d}$ & 0.92 & $0.70-1.22$ & 2.89 & $2.04-4.11^{* * *}$ & 0.95 & $0.84-1.08$ \\
\hline \multicolumn{7}{|l|}{ Sector of exploitation } \\
\hline $\begin{array}{l}\text { Forced marriage, entertainment, dancing, domestic work, } \\
\text { cleaner, restaurant work, begging, and other (reference) }\end{array}$ & 1.0 & & 1.0 & & 1.0 & \\
\hline Animal, farming, agriculture, and fishing & 1.03 & $0.58-1.81$ & 1.23 & $0.64-2.34$ & 1.37 & $0.81-2.32$ \\
\hline Construction and factory work & 1.40 & $0.76-2.57$ & 1.27 & $0.85-1.89$ & 1.34 & $0.94-1.91$ \\
\hline \multicolumn{7}{|l|}{ Time in trafficking situation (months) } \\
\hline 1-12 (reference) & 1.0 & & 1.0 & & 1.0 & \\
\hline 13 or more & 2.31 & $1.28-4.16^{* *}$ & 1.22 & $0.48-3.11$ & 1.02 & $0.60-1.74$ \\
\hline $\begin{array}{l}{ }_{p} p \leq 0.05 \\
{ }^{* *} p \leq 0.01 \\
\text { a } p \leq 0.001 \\
\text { aPTSD Post-traumatic stress disorder } \\
\text { bPR Prevalence ratio } \\
\text { c95\% Confidence interval } \\
\text { dOther country of exploitation included Cambodia Malavsia Vietn }\end{array}$ & . & 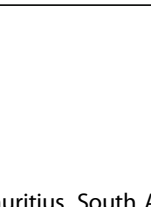 & - & & & \\
\hline
\end{tabular}

were exploited in different labor sectors. We found that violence and coercion (receiving personal threats or both personal and family threats) are both independently associated with poor mental health and differed between females and males. For females, experiencing both physical and sexual violence was a strong predictor of symptoms of anxiety, PTSD, and depression, while for males, physical violence with additional threats made with weapons was strongly associated with symptoms of PTSD.

Another key finding in the study was that acts of coercion (personal and both personal and family threats) during the trafficking experience proved to be consistently and strongly associated with anxiety, depression, and PTSD symptoms in both females and males. Coercion in females was particularly strongly related to anxiety and PTSD among those receiving both personal and family threats. This finding on the influence of threats is consistent with previous research on trafficked women [28]. Our results highlight the different coercive experiences between females and males, and indicate that coercion can be as harmful to mental health as any form of physical violence.

Overall, the study results are consistent with past studies of gender-based violence and health trafficking research that report sexual and physical violence to be salient features of the trafficking experience among females $[4,12,28,30,32,34]$. Previous research on human trafficking, gender-based violence and interpersonal violence indicates that experiencing more than one type of abuse (e.g., physical, sexual, and psychological or emotional) increases the probability of having anxiety, depression, or PTSD symptoms as well as the severity of those symptoms [34, 59-62]. Likewise, our results are in accordance with interpersonal violence (IPV) research that reports that psychological coercion for both men and women is strongly associated with an increased risk of symptoms of depression and PTSD [63-65].

In sum, violence and coercion for many trafficked individuals is a central element of the trafficking experience $[4,34,66]$, and it was a salient feature in the present study. The systematic implementation of coercive tactics used by perpetrators reinforces control, depletes individual psychological resources and ultimately contributes to poor mental health $[4,6]$. Sexual and physical violence are powerful methods to terrorize, dominate, and humiliate the enslaved individual, but sexual violence in particular is intentionally meant to produce psychological trauma [4, $15,66]$. We found that experiencing both sexual and physical violence was strongly associated with poor mental health in women and girls. 
Table 6 Crude and adjusted prevalence ratios of the association of violence and coercion (threats) with anxiety, post-traumatic stress disorder, and depression in trafficked males, $n=446$

\begin{tabular}{|c|c|c|c|c|c|c|}
\hline & \multicolumn{2}{|c|}{ Unadjusted Model } & \multicolumn{2}{|c|}{ Adjusted Model $1^{a}$} & \multicolumn{2}{|c|}{ Adjusted Model $2^{\mathrm{b}}$} \\
\hline & $\overline{\mathrm{PR}^{\mathrm{C}}}$ & $95 \% \mathrm{Cl}^{d}$ & $\overline{P R}$ & $95 \% \mathrm{Cl}$ & $\overline{P R}$ & $95 \% \mathrm{Cl}$ \\
\hline \multicolumn{7}{|l|}{ Anxiety } \\
\hline \multicolumn{7}{|l|}{ Violence } \\
\hline No violence (reference) & 1.0 & & 1.0 & & & \\
\hline Physical violence additional with threats made with weapons & 1.49 & $1.00-2.19^{*}$ & 1.41 & $0.86-2.31$ & & \\
\hline \multicolumn{7}{|l|}{ Receiving threats during trafficking } \\
\hline None (reference) & 1.0 & & & & 1.0 & \\
\hline Personal threats & 1.36 & $1.14-1.62^{* * *}$ & & & 1.33 & $1.08-1.64^{* *}$ \\
\hline Both personal and family threats & 1.64 & $1.40-1.92^{* * *}$ & & & 1.68 & $1.43-1.97^{* * *}$ \\
\hline \multicolumn{7}{|l|}{ Post-Traumatic Stress Disorder } \\
\hline \multicolumn{7}{|l|}{ Violence } \\
\hline No violence (reference) & 1.0 & & 1.0 & & & \\
\hline Physical violence with additional threats made with weapons & 1.60 & $0.92-2.78$ & 1.59 & $1.05-2.42^{*}$ & & \\
\hline \multicolumn{7}{|l|}{ Receiving threats during trafficking } \\
\hline None (reference) & 1.0 & & & & 1.0 & \\
\hline Personal threats & 1.80 & $1.39-2.35^{* * *}$ & & & 1.75 & $1.51-2.03^{* * *}$ \\
\hline Both personal and family threats & 1.92 & $1.65-2.24^{* * *}$ & & & 1.62 & $1.31-2.00^{* * *}$ \\
\hline \multicolumn{7}{|l|}{ Depression } \\
\hline \multicolumn{7}{|l|}{ Violence } \\
\hline No violence (reference) & 1.0 & & 1.0 & & & \\
\hline Physical violence with additional threats made with weapons & 1.39 & $0.83-2.33$ & 1.47 & $0.91-2.36$ & & \\
\hline \multicolumn{7}{|l|}{ Receiving threats during trafficking } \\
\hline None (reference) & 1.0 & & & & 1.0 & \\
\hline Personal threats & 1.39 & $1.28-1.50^{* * *}$ & & & 1.46 & $1.35-1.57^{* * *}$ \\
\hline Both personal and family threats & 1.42 & $1.24-1.62^{* * *}$ & & & 1.33 & $1.11-1.58^{* * *}$ \\
\hline
\end{tabular}

Models for anxiety, depression, and post-traumatic stress disorder were run separately but they were adjusted for the same variables ${ }^{*} p \leq 0.05$

${ }_{* * *}^{* *} \leq \leq 0.01$

${ }^{* * *} p \leq 0.001$

${ }^{a}$ Adjusted Model 1 (violence): age, country of exploitation, sector of exploitation, time in trafficking

${ }^{\mathrm{b}}$ Adjusted Model 2 (coercion or threats): age, country of exploitation, sector of exploitation, time in trafficking

CPR Prevalence ratio

d $95 \%$ Confidence interval

Beyond the trauma, sexual violence is also associated with an increased risk of human immunodeficiency virus (HIV) and other sexually transmitted diseases that can exacerbate physical and mental health problems [67]. Therefore, experiencing both types of violence, sexual and physical, may be an added burden to the harm inflicted on the mental health of female trafficking survivors.

Physical violence with additional threats made with weapons was an important risk factor for PTSD for males in this population. Threats with weapons are another common method to exert psychological coercion, but this is the first study to document this impact in a population of male survivors of trafficking $[4,68]$. However, our finding is consistent with the relatively scant research about the nonfatal use of weapons in the context of interpersonal violence $[69,70]$. Threats with weapons allow the aggressor to assert dominance in interpersonal relationships because they convey a pernicious threat, elicit compliance, and create extreme fear and intimidation, all of which are the hallmarks for coercive control $[69,70]$. Psychological coercive control, a key feature of human trafficking, is known to have deleterious effects on mental health as it involves terror, fear, isolation, and helplessness which consequently affects an individual's self-efficacy and autonomy $[3,6,64]$.

Although the female burden of suffering both physical and sexual violence was expected and documented in previous research $[26-29,34,71]$, the elevated prevalence for anxiety, depression, and PTSD in this population is of 
considerable concern. Similar elevated prevalence of depression and PTSD had been observed among populations exposed to mass conflict and displacement in which torture and trauma emerged as the strongest risk factor for PTSD and depression [72]. Overall, these findings are consistent with previous research that highlights the need to amplify our understanding of the diversity and complexity of what constitutes human trafficking and how it is carried out globally in diverse countries and through many labor sectors for females and males $[34,73]$.

An important limitation of this analysis is the cross-sectional design; hence causality and the temporal relationship between violence, threats, and mental health symptoms (anxiety, PTSD, and depression) cannot be established. Individuals with poor mental health could be more vulnerable to being trafficked or have a history of violence. However, previous studies on human trafficking, violence and women's health suggest that mental health problems are more likely to be the result of abuse rather than its precursor [3, 26, 67, 74]. Assessment of mental health symptoms was conducted with screening instruments with robust psychometric properties. These instruments are commonly used in general populations in some of the study countries and in post-trafficking services. However, these instruments are not gold-standard diagnostic tools to clinically assess these disorders, therefore overestimation of the prevalence ratio of mental health outcomes is possible. It is also plausible that trafficked individuals under the harshest forms of slavery and exploitation are the ones with worse mental health and may be less likely to be reached in post-trafficking services. In this case, our estimates of the prevalence ratio will be underestimates. Nonetheless, the direction and magnitude of the associations observed are consistent with similar previous studies [26, 30, 32, 34].

The study population represents a sample of survivors of trafficking using post-trafficking services. Service eligibility and screening processes for referral to post-trafficking services may vary between countries as human trafficking is often defined according to the legal framework of the country. Therefore, the results of the study may not be generalizable to the broader population of trafficked individuals. However, this population is likely to be representative of survivors of trafficking receiving post-trafficking services in similar forced labor conditions in the countries in question, as violence and coercion are known to be core components of any human trafficking situation.

Another plausible limitation is underreporting of sexual violence in males. Overall, research on sexual abuse and sexual assault of men and boys in all settings is scarce $[75,76]$. Previous studies indicate that the perpetration of sexual violence in males is more common in boys than in adult males [77-79]. Children, in particular, rarely disclose sexual abuse after the event, and disclosure tends to be a process rather than a single question or interview [76]. Male adults are more likely to be sexually assaulted by multiple assailants and to have weapons used against them [80, 81]. Sexual abuse and violence against trafficked males needs further research as well as consideration of the role that culture plays in sexual violence.

The study has important clinical, public health, and policy implications. The elevated prevalence of anxiety, depression, and PTSD in this sample of survivors indicates that addressing their mental health needs is complex and requires a coordinated, culturally sensitive, holistic, and multi-tiered system approach. Care should include immediate and continuous services (e.g., mental and physical health, social services, safety, housing, legal counsel, economic aid, and community and societal reintegration), which should be provided regardless of an individual's country of origin, legal status, or participation in legal proceedings against traffickers. Building a network of services prepared to address the complex needs that survivors face after being trafficked is needed [7, 82].

A fundamental element of care for trafficked individuals should involve a collaborative approach and a safe space that prioritizes empowerment of survivors. Service providers need to respect survivors' perspectives, and acknowledge their rights. Given the diverse demographic background and traumatic experiences endured by trafficked individuals, it is important that service providers be well trained with strong multicultural competencies and knowledge of the various forms of exploitation, abuse, and violence as well as ways to screen for potential cases of human trafficking.

Poor mental health and exposure to traumatic events that involve violence can have long lasting health effects, this is particularly concerning for children and adolescents. Yet, to date, the efficacy of psychological treatments for survivors of human trafficking in Southeast Asia has not been investigated. Western treatments may not fully capture the complexity of the psychological responses that arise from individuals who have experienced human rights violations [83]. However, evidence -based treatments, such as Narrative Exposure Therapy (NET) or Trauma-Focused Cognitive-Behavioral Therapy (TF-CBT), have been used with female survivors of sex trafficking and refugees [84-86]. NET was originally developed for multiple traumatized victims of organized violence in resource-poor settings, where it could be delivered by trained non-professionals [84]. A modified version of TF-CBT has been developed for children exposed to multiple complex traumas, and it is commonly used in children and adolescents with PTSD [87]. Systematic evaluation on the implementation, delivery, and outcomes of mental health interventions is essential for treatment programs, stakeholders and policy makers to 
improve care and bring accountability to the care of trafficking survivors.

\section{Conclusions}

In conclusion, it is important for policy makers and stakeholders to consider the complex and severe effects that violence and coercion inflict on the mental health of survivors of trafficking. We observed differences in the experiences of violence and coercion in female and male trafficking survivors. We found a substantially elevated prevalence of anxiety $(\approx 40.0 \%)$, depression (>50\%), and PTSD (> 35\%) among survivors of trafficking compared to estimates of the general population in Cambodia $(\approx 3.2-3.4 \%)$, Thailand $(\approx 3.5-4.4 \%)$, and Vietnam $(\approx 2.2-4.0 \%)$, respectively [88]. Our findings highlight the importance of mental health treatment as an integral part of service provision, recovery and re-integration for female and male survivors. Strengthening mechanisms to protect survivors of trafficking and family members susceptible to retaliation and coercion from traffickers is critical. Further research on the development and implementation of evidence based mental health treatments for survivors of trafficking is warranted. Public health interventions and epidemiological approaches could be valuable to furthering understanding of human slavery within a health equity framework to strengthen individuals' and communities' capacities to prevent and address forced labor globally.

\section{Abbreviations \\ Cl: Confidence intervals; DSM: Diagnostic and Statistical Manual of the American Psychiatric Association; GEE: Generalized estimation equations; HSCL-25: Hopkins Symptom Checklist-25; HTQ: Harvard Trauma Questionnaire; ILO: International Labour Organization; IOM: International Office of Migration; IPV: Interpersonal violence; LK: Ligia Kiss; LSHTM: London School of Hygiene and Tropical Medicine; NET: Narrative exposure therapy; PRs: Prevalence ratios; PTSD: Post-traumatic stress disorder; QIC: Quasi- likelihood under the Independence Model Criterion; SD: Standard deviation; STEAM: Study on Trafficking, Exploitation and Abuse in the Mekong Sub- region; TF-CBT: Trauma-Focused Cognitive-Behavioral Therapy; WHO: World Health Organization}

\section{Acknowledgements}

We are grateful to Dr. Nicola S. Pocock for her valuable guidance and assistance with the STEAM dataset and documentation.

\section{Funding}

This manuscript was developed without funding.

\section{Availability of data and materials}

The datasets generated during and/or analyzed during the current study are not publicly available due to safety concerns and the confidentiality agreement obligations with study participants. Data is available to qualifying researchers upon reasonable request from the Principal Investigator of STEAM (Dr. Ligia Kiss).

\section{Authors' contributions}

All authors assisted with the study conception and design, critical review of the manuscript, editing, and approval of the final version of the manuscript. LIR conceptualized and wrote the first draft, reviewed the final draft, and conducted statistical analyses. SH reviewed statistical analyses and provide overall supervision of the research. SB was involved in revising the manuscript critically for important intellectual content. CZ and LK collected the data and supervised the implementation of the STEAM study.

\section{Authors' information}

LIR is a PhD level epidemiologist with interests in addressing human trafficking and labor explotation in females and males through research, advocacy and policy. SH is a professor of epidemiology and global public health. $\mathrm{SH}$ is the director of the Center for Midlife Science at the School of Public Health, University of Michigan. SB is an associate professor of sociology, joint associate professor of epidemiology, and research assistant professor in the Population Studies Center at the University of Michigan. SB studies the social determinants of health disparities by gender, race/ethnicity and socioeconomic positions across societies. LK is an assistant professor of social epidemiology at the Gender Violence and Health Centre at the London School of Hygiene and Tropical Medicine (LSHTM). CZ is a professor and founder of the Gender Violence and Health Centre at the LSHTM. Both LK and CZ are experts in the field of human trafficking with years of experience in policy and service-focused evidence from various countries in Asia, Latinoamerica and Europe.

\section{Ethics approval and consent to participate}

Ethical approval for the study was granted by the LSHTM and by the National Ethics Committee for Health Research in Cambodia, the Hanoi School of Public Health in Vietnam, and the Ministry of Social Development and Human Security in Thailand. Core ethical guidance included measures to ensure that participation was voluntary and confidential, assurance that declining participation would not affect the provision of support services, avoidance and management of distress, and the offering of options for supported referral for health or other problems. The secondary analysis was approved by the University of Michigan Health Sciences and Behavioral Sciences Institutional Review Board, eResearch ID: HUM00097096.

\section{Consent for publication}

Not applicable.

\section{Competing interests}

The authors declare that they have no competing interests.

\section{Publisher's Note}

Springer Nature remains neutral with regard to jurisdictional claims in published maps and institutional affiliations.

\section{Author details}

${ }^{1}$ Department of Epidemiology, School of Public Health, University of Michigan, 1415 Washington Heights, Ann Arbor, MI 48109, USA. ²Department of Sociology, College of Literature Science, and the Arts, University of Michigan, Ann Arbor, MI, USA. ${ }^{3}$ Gender Violence and Health Centre, Department of Global Health and Development, London School of Hygiene and Tropical Medicine, London, UK.

Received: 8 August 2018 Accepted: 12 November 2018 Published online: 12 December 2018

\section{References}

1. United Nations, General Assembly. Protocol to prevent, supress, and punish trafficking in persons, especially women and children, supplementing the United Nations convention against transnational organized crime. In: United Nations, Office on Drugs and Crime, editor. United Nations convention against transnational organized crime and the protocols thereto. New York: United Nations; 2004. p. 41-52.

2. Global estimates of modern slavery: forced labour and forced marriage. Geneva: International Labour Organization; 2017. http://www.ilo.org/global/ publications/books/WCMS_575479/lang\%2D\%2Den/index.htm. Accessed 23 Jan 2018.

3. Herman JL. Trauma and recovery: the afthermath of violence -from domestic abuse to political terror. New York: Basic Books; 2015.

4. Hopper E, Hidalgo J. Invisible chains: psychological coercion of human trafficking victims. Intercult Hum Rights Law Rev. 2006;1:185-210.

5. United Nations Office on Drugs and Crime (UNODC). Abuse of a position of vulnerability and other "means" within the definition of trafficking in persons. New York: United Nations; 2013. 
6. Baldwin SB, Fehrenbacher AE, Eisenman DP. Psychological coercion in human trafficking: an application of Biderman's framework. Qual Health Res. 2015;25(9):1171-81. https://doi.org/10.1177/1049732314557087.

7. Bales K, Fletcher L, Stover E. Hidden slaves: forced labor in the United States. Berkeley J Int Law. 2004;23(1):47.

8. Brunovskis A, Surtees R. Untold stories: biases and selection effects in research with victims of trafficking for sexual exploitation. Int Migr. 2010; 48(4):1-37. https://doi.org/10.1111/j.1468-2435.2010.00628.x.

9. Palmer $\mathrm{N}$. The essential role of social work in addressing victims and survivors of trafficking. ILSA J Int Law. 2010;17(1):43-56.

10. Zimmerman C, Schenker MB. Human trafficking for forced labour and occupational health. Occup Environ Med. 2014;71(12):807-8. https://doi.org/ 10.1136/oemed-2014-102452

11. Zimmerman C, Hossain M, Watts C. Human trafficking and health: a conceptual model to inform policy, intervention and research. Soc Sci Med. 2011;73(2):327-35. https://doi.org/10.1016/j.socscimed.2011.05.028.

12. Feingold DA. Human Trafficking. Foreign Policy. 2005;150:26-32.

13. Garcia-Moreno C, Jansen HA, Ellsberg M, Heise L, Watts C. WHO multicountry study on women's health and domestic violence against women. Geneva: World Health Organization; 2005.

14. Zimmerman C, Yun K, Watts C, Shvab I, Trappolin L, Treppete M, et al. The health risks and consequences of trafficking in women and adolescents: findings from a European study. London: London School of Hygiene \& Tropical Medicine; 2003. Supported by the European Commission's Daphne Programme

15. Kara S. Sex trafficking: inside the business of modern slavery. New York: Columbia University Press; 2009. p. 298.

16. Zimmerman C, Kiss L. Human trafficking and exploitation: a global health concern. PLoS Med. 2017;14(11):e1002437. https://doi.org/10.1371/journal. pmed. 1002437.

17. Zimmerman C, Kiss L, Houssain M, Watts C. Trafficking in persons: a health concern? Cien Saude Colet. 2009:14(4):1029-35. https://doi.org/10.1590/ S1413-81232009000400010

18. Mollica RF. Surviving torture. N Engl J Med. 2004;351(1):5-7. https://doi.org/ 10.1056/NEJMp048141

19. Johnson $\mathrm{H}$, Thompson A. The development and maintenance of posttraumatic stress disorder (PTSD) in civilian adult survivors of war trauma and torture: a review. Clin Psychol Rev. 2008;28(1):36. https://doi.org/10.1016/j. cpr.2007.01.017.

20. Herman JL. Complex PTSD: a syndrome in survivors of prolonged and repeated trauma. J Trauma Stress. 1992;5(3):377-91. https://doi.org/10.1007/BF00977235.

21. Horowitz M. Post-traumatic stress disorders: psychosocial aspects of the diagnosis. Int J Ment Health. 1990;19(1):21 http://www.jstor.org/stable/ 41337343.

22. Hougen HP. Physical and psychological sequelae to torture. A controlled clinical study of exiled asylum applicants. Forensic Sci Int. 1988;39(1):5-11. https://doi.org/10.1016/0379-0738(88)90113-2.

23. Somnier FE, Genefke IK. Psychotherapy for victims of torture. Br J Psychiatry. 1986;149(3):323-9. https://doi.org/10.1192/bjp.149.3.323.

24. Song SJ, Subica A, Kaplan C, Tol W, de Jong J. Predicting the mental health and functioning of torture survivors. J Nerv Ment Dis. 2017;206(1):33-9. https://doi.org/10.1097/NMD.0000000000000678.

25. Muldoon KA, Deering KN, Feng CX, Shoveller JA, Shannon K. Sexual relationship power and intimate partner violence among sex workers with non-commercial intimate partners in a Canadian setting. AIDS Care. 2015; 27(4):512-9. https://doi.org/10.1080/09540121.2014.978732.

26. Ottisova L, Hemmings S, Howard LM, Zimmerman C, Oram S. Prevalence and risk of violence and the mental, physical and sexual health problems associated with human trafficking: an updated systematic review. Epidemiol Psychiatr Sci. 2016;25(4):317-41. https://doi. org/10.1017/S2045796016000135.

27. Oram S, Stöckl H, Busza J, Howard LM, Zimmerman C, et al. PLoS Med. 2012; 9(5):e1001224. https://doi.org/10.1371/journal.pmed.1001224.

28. Zimmerman C, Hossain M, Yun K, Roche B, Morison L, Watts C. Stolen smiles: a summary report on the physical and psychological health consequences of women and adolescents trafficked in Europe. London: London School of Hygiene \& Tropical Medicine; 2006. Supported by the European Commission's Daphne Programme and the International Organization of Migration

29. Kiss L, Yun K, Pocock N, Zimmerman C. Exploitation, violence, and suicide risk among child and adolescent survivors of human trafficking in the greater Mekong subregion. JAMA Pediatr. 2015;169(9):e152278. https://doi org/10.1001/jamapediatrics.2015.2278.

30. Hossain M, Zimmerman C, Abas M, Light M, Watts C. The relationship of trauma to mental disorder among trafficked and sexually exploited girls and women. Am J Public Health. 2010;100(12):2442-9. https://doi.org/10.2105/ AJPH.2009.173229.

31. Tsutsumi A, Izutsu T, Poudyal AK, Kato S, Marui E. Mental health of female survivors of human trafficking in Nepal. Soc Sci Med. 2008;66(8):1841-7. https://doi.org/10.1016/j.socscimed.2007.12.025.

32. Zimmerman C, Hossain M, Yun K, Gajdadziev V, Guzun N, Tchomarova M, et al. The health of trafficked women: a survey of women entering posttrafficking services in Europe. Am J Public Health. 2008;98(1):55-9. https://doi.org/10.2105/AJPH.2006.108357.

33. Abas M, Ostrovschi NV, Prince M, Gorceag VI, Trigub C, Oram S. Risk factors for mental disorders in women survivors of human trafficking: a historical cohort study. BMC Psychiatry. 2013;13(204):2-11. https://doi.org/10.1186/ 1471-244X-13-204

34. Kiss L, Pocock NS, Naisanguansri V, Suos S, Dickson B, Thuy D, et al. Health of men, women, and children in post-trafficking services in Cambodia, Thailand, and Vietnam: an observational cross-sectional study. Lancet Glob Health. 2015:3(3):e154-61. https://doi.org/10.1016/S2214-109X(15)70016-1.

35. Oram S, Khondoker M, Abas M, Broadbent M, Howard LM. Characteristics of trafficked adults and children with severe mental illness: a historical cohort study. Lancet Psychiatry. 2015;2(12):1084-91. https://doi.org/10.1016/S22150366(15)00290-4.

36. Turner-Moss E, Zimmerman C, Howard LM, Oram S. Labour exploitation and health: a case series of men and women seeking post-trafficking services. J Immigr Minor Health. 2014;16(3):473-80. https://doi.org/10.1007/s10903-0139832-6.

37. Zimmerman C, Watts C. WHO ethical and safety recommendations for interviewing trafficked women. Reprod Health Matters. 2003:1-29. http:// apps.who.int/iris/handle/10665/42765. Accessed 23 Jan 2018.

38. Derogatis LR, Lipman RS, Rickels K, Uhlenhuth EH, Covi L. The Hopkins Symptom Checklist (HSCL): a self report symptom inventory. Behav Sci. 1974;19(1):1-15. https://doi.org/10.1002/bs.3830190102.

39. American Psychiatric Association. Diagnostic and statistical manual of mental disorders. 4th ed. Washington: The Association; 1994.

40. Mollica RF, Donelan K, Tor S, Lavelle J, Elias C, Frankel M, et al. The effect of trauma and confinement on functional health and mental health status of Cambodians living in Thailand-Cambodia border camps. JAMA. 1993;270(5): 581-6. https://doi.org/10.1001/jama.270.5.581.

41. Mollica RF, Wyshak G, de Marneffe D, Khuon F, Lavelle J. Indochinese versions of the Hopkins Symptom Checklist-25: a screening instrument for the psychiatric care of refugees. Am J Psychiatry. 1987; 144(4):497-500.

42. Harvard trauma questionnaire (HTQ) [Internet]. Cambridge (MA): Harvard Program in Refugee Trauma. http://hprt-cambridge.org/screening/harvardtrauma-questionnaire/. Accessed 23 Jan 2018.

43. Mollica R, Caspi-Yavin Y, Lavelle J, Tor S, Yang T, Chan S, Pham T, Ryan A, de Marneffe D. Harvard trauma questionnaire (HTQ) manual: Cambodian, Lao, and Vietnamese versions. Torture. 1996:6(1):19-33.

44. Van der Kolk B. Posttraumatic stress disorder and the nature of trauma. Dialogues Clin Neurosci. 2000;2(1):7-22.

45. Silove D, Steel Z, Mollica RF. Detention of asylum seekers: assault on health, human rights, and social development. Lancet. 2001:357(9266):1436-7. https://doi.org/10.1016/S0140-6736(00)04575-X.

46. Kleijn WC, Hovens JE, Rodenburg JJ. Posttraumatic stress symptoms in refugees: assessments with the Harvard Trauma Questionnaire and the Hopkins symptom checklist-25 in different languages. Psychol Rep. 2001; 88(2):527-32. https://doi.org/10.2466/PR0.88.2.527-532.

47. Mollica RF, Caspi-Yavin Y. Measuring torture and torture-related symptoms. Psychol Assess. 1991;3(4):581-7. https://doi.org/10.1037/10403590.3.4.581.

48. Mollica RF, Caspi-Yavin Y, Bollini P, Truong T, Tor S, Lavelle J. The Harvard Trauma Questionnaire-validating a cross-cultural instrument for measuring torture, trauma, and posttraumatic stress disorder in Indo-chinese refugees. J Nerv Ment Dis. 1992;180(2):111-6. https://doi.org/10.1097/00005053199202000-00008.

49. Ekblad S, Roth G. Diagnosing posttraumatic stress disorder in multicultural patients in a Stockholm psychiatric clinic. J Nerv Ment Dis. 1997:185(2):1027. https://doi.org/10.1097/00005053-199702000-00006. 
50. Kelly JB, Johnson MP. Differentiation among types of intimate partner violence: research update and implication for interventions. Fam Court Rev. 2008;46(3):476-99

51. Watts C, Zimmerman C. Violence against women: global scope and magnitude. Lancet. 2002;359(9313):1232-7. https://doi.org/10.1016/S01406736(02)08221-1.

52. Kristen E, Banuelos B, Urban D. Workplace violence and harassment of lowwage workers. Berkeley J Employ Labor Law. 2015;36(1):169-214.

53. Rao JN, Scott AJ. A simple method for the analysis of clustered binary data. Biometrics. 1992;48(2):577-85. https://doi.org/10.2307/2532311.

54. Zou G. A modified Poisson regression approach to prospective studies with binary data. Am J Epidemiol. 2004;159(7):702-6. https://doi.org/10.1093/aje/ kwh090.

55. Royall RM. Model robust confidence intervals using maximum likelihood estimators. Int Stat Rev. 1986;54(2):221-6. https://doi.org/10.2307/1403146.

56. Yelland LN, Salter AB, Ryan P. Performance of the modified Poisson regression approach for estimating relative risks from clustered prospective data. Am J Epidemiol. 2011;174(8):984-92. https://doi.org/10.1093/aje/kwr183.

57. Zou GY, Donner A. Extension of the modified Poisson regression model to prospective studies with correlated binary data. Stat Methods Med Res. 2013;22(6):661-70. https://doi.org/10.1177/0962280211427759.

58. Usage note 23109: assessing choice of GEE working correlation structure [Internet]. Cary: SAS Institute. Available from: http://support.sas.com/kb/23/ 109.html. Cited 23 Jan 2018.

59. The GENMOD procedure [Internet]. Cary: SAS Institute. https://support.sas. com/documentation/cdl/en/statug/63033/HTML/default/viewer. htm\#genmod_toc.htm. Accessed 23 Jan 2018.

60. Pico-Alfonso MA, Garcia-Linares MI, Celda-Navarro N, Blasco-Ros C, Echeburúa E, Martinez M. The impact of physical, psychological, and sexual intimate male partner violence on women's mental health: depressive symptoms, posttraumatic stress disorder, state anxiety, and suicide. J Women's Health (Larchmt). 2006;15(5):599-611. https://doi.org/10.1089/jwh. 2006.15.599

61. Houry D, Kemball R, Rhodes KV, Kaslow NJ. Intimate partner violence and mental health symptoms in African American female ED patients. Am J Emerg Med. 2006;24(4):444-50. https://doi.org/10.1016/j.ajem.2005.12.026.

62. Savas N, Agridag G. The relationship between women's mental health and domestic violence in semirural areas: a study in Turkey. Asia Pac J Public Health. 2011;23(3):399-407.

63. Coker AL, Davis KE, Arias I, Desai S, Sanderson M, Brandt HM, et al. Physical and mental health effects of intimate partner violence for men and women. Am J Prev Med. 2002;23(4):260-8. https://doi.org/10.1016/S07493797(02)00514-7.

64. Mechanic MB, Weaver TL, Resick PA. Mental health consequences of intimate partner abuse. Violence Against Women. 2008;14(6):634-54. https:// doi.org/10.1177/1077801208319283.

65. Basile KC, Arias I, Desai S, Thompson MP. The differential association of intimate partner physical, sexual, psychological, and stalking violence and posttraumatic stress symptoms in a nationally representative sample of women. J Trauma Stress. 2004;17(5):413-21. https://doi.org/10.1023/B:JOTS 0000048954.50232.d8.

66. Fletcher L, Bales K, Stover E. Hidden slaves: forced labor in the United States. Berkeley J Int Law. 2005;23(1):47-111.

67. World report on violence and health. Albany: World Health Organization; 2002. http://www.who.int/violence injury_prevention/violence/world report/en/. Accessed 23 Jan 2018.

68. 2017 trafficking in persons report. Washington: US Department of State; 2017 Jun. https://www.state.gov/j/tip/rls/tiprpt/2017/. Accessed 23 Jan 2018.

69. Sorenson SB, Schut RA. Nonfatal gun use in intimate partner violence. Trauma Violence Abuse. 2016. https://doi.org/10.1177/1524838016668589.

70. Sorenson SB. Guns in intimate partner violence: comparing incidents by type of weapon. J Women's Health (Larchmt). 2017;26(3):249-58. https://doi. org/10.1089/jwh.2016.5832

71. World Health Organization \& Pan American Health Organization. Understanding and addressing violence against women: human trafficking. World Health Organization. 2012. http://www.who.int/iris/handle/10665/ 77394. Accessed 23 Jan 2018.

72. Steel Z, Chey T, Silove D, Marnane C, Bryant RA, van Ommeren M. Association of torture and other potentially traumatic events with mental health outcomes among populations exposed to mass conflict and displacement: a systematic review and meta-analysis. JAMA. 2009;302(5): 537-49. https://doi.org/10.1001/jama.2009.1132.

73. Pocock NS, Kiss L, Oram S, Zimmerman C. Labour trafficking among men and boys in the greater Mekong subregion: exploitation, violence, occupational health risks and injuries. PLoS One. 2016;11(12):e0168500. https://doi.org/10.1371/journal.pone.0168500.

74. Campbell JC. Health consequences of intimate partner violence. Lancet 2002;359(9314):1331-6. https://doi.org/10.1016/S0140-6736(02)08336-8.

75. Masho SW, Alvanzo A. Help-seeking behaviors of men sexual assault survivors. Am J Mens Health. 2010;4(3):237-42. https://doi.org/10.1177/ 1557988309336365.

76. Guidelines for medico-legal care of victims of sexual violence. Geneva: World Health Organization; 2003. http://www.who.int/violence injury prevention/ publications/violence/med_leg_guidelines/en/. Accessed 10 Mar 2018.

77. Briere J, Elliott DM. Prevalence and psychological sequelae of self-reported childhood physical and sexual abuse in a general population sample of men and women. Child Abuse Negl. 2003;27(10):1205-22. https://doi.org/10. 1016/j.chiabu.2003.09.008.

78. Fergusson DM, McLeod GF, Horwood LJ. Childhood sexual abuse and adult developmental outcomes: findings from a 30-year longitudinal study in New Zealand. Child Abuse Negl. 2013;37(9):664-74. https://doi.org/10.1016/j. chiabu.2013.03.013.

79. Dube SR, Anda RF, Whitfield CL, Brown DW, Felitti VJ, Dong M, et al. Long term consequences of childhood sexual abuse by gender of victim. Am J Prev Med. 2005;28(5):430-8. https://doi.org/10.1016/j.amepre.2005.01.015.

80. Kimerling $R$, Rellini $A$, Kelly $V$, Judson PL, Learman LA. Gender differences in victim and crime characteristics of sexual assaults. J Interpers Violence. 2002; 17(5):526-32. https://doi.org/10.1177/0886260502017005003.

81. Frazier P. A comparative study of male and female rape victims seen at a hospital-based rape crisis program. J Interpers Violence. 1993;8(1):64-76. https://doi.org/10.1177/088626093008001005.

82. Powell C, Asbill M, Louis E, Stoklosa H. Identifying gaps in human trafficking mental health service provision. J Hum Trafficking. 2018;4(3):256-69.

83. Marsella AJ. Ethnocultural aspects of PTSD: an overview of concepts, issues, and treatments. Traumatology. 2010;16(4):17-26 doi: 0.1177/ 1534765610388062.

84. Neuner F, Schauer M, Klaschik C, Karunakara U, Elbert T. A comparison of narrative exposure therapy, supportive counseling, and psychoeducation for treating posttraumatic stress disorder in an African refugee settlement. J Consult Clin Psychol. 2004;72(4):579-87. https://doi.org/10.1037/0022-006X.72.4.579.

85. Robjant K, Roberts J, Katona C. Treating posttraumatic stress disorder in female victims of trafficking using narrative exposure therapy: a retrospective audit. Front Psychiatry. 2017;8:63. https://doi.org/10.3389/fpsyt. 2017.00063

86. O'Callaghan P, McMullen J, Shannon C, Rafferty H, Black A. A randomized controlled trial of trauma-focused cognitive behavioral therapy for sexually exploited, war-affected Congolese girls. J Am Acad Child Adolesc Psychiatry. 2013;52(4):359-69. https://doi.org/10.1016/j.jaac.2013.01.013.

87. National Collaborating Centre for Mental Health (UK). Post-traumatic stress disorder: the management of PTSD in adults and children in primary and secondary care. Leicester: Gaskel; 2005. (National Institute for Health and Clinical Excellence: guidance). The Royal College of Psychiatrists \& The British Psychological Society. 2005

88. World Health Organization. Depression and other common mental disorders: global health estimates. 2017. https://www.who.int/mental health/management/depression/prevalence_global_health_estimates/en/. Accessed 23 Oct 2018

Ready to submit your research? Choose BMC and benefit from:

- fast, convenient online submission

- thorough peer review by experienced researchers in your field

- rapid publication on acceptance

- support for research data, including large and complex data types

- gold Open Access which fosters wider collaboration and increased citations

- maximum visibility for your research: over $100 \mathrm{M}$ website views per year

At BMC, research is always in progress.

Learn more biomedcentral.com/submission 